\title{
Attention to Intentions-How to Stimulate Strong Intentions to Change
}

\author{
M. Dam ${ }^{1,2}$ • F. J. J. M. Janssen ${ }^{3,4}$ • J. H. van Driel ${ }^{3,4}$
}

Published online: 14 April 2017

(C) The Author(s) 2016. This article is published with open access at Springerlink.com

\begin{abstract}
The implementation of educational reforms requires behavioral changes from the teachers involved. Theories on successful behavioral change prescribe the following conditions: teachers need to possess the necessary knowledge and skills, form strong positive intentions to perform the new behavior, and have a supporting environment for change. However, existing approaches to teacher professional development in the context of educational reforms are predominantly aimed at the development of knowledge and skills and at creating a supporting environment, but lack attention to teachers' intentions to change. In the study described in this article, we performed "motivating-for-educational-change" interviews (MECI) and explored the influence on teachers' intentions to change in the direction of the proposed national biology education reform, that is, the introduction of a context-based curriculum. The MECI comprised two tools: building on earlier successful experiences and using lesson segments to rearrange instructional approaches. We explored the influence of the MECI technique on the strength and specificity of participating teachers' intentions. When conducting the MECI, many participants expressed that they now realized how they had already implemented aspects of the reform in their regular instructional approaches. Furthermore, all the participants formulated stronger and more specific intentions to change their
\end{abstract}

Affiliation where research was conducted: Leiden University, ICLON

M. Dam

m.dam@uva.nl

F. J. J. M. Janssen

fjanssen@iclon.leidenuniv.nl

J. H. van Driel

Driel@iclon.leidenuniv.nl

1 ILO, University of Amsterdam, Nieuwe Achtergracht 127, 1018 WS Amsterdam, Netherlands

2 Postbus 15782, 1001 NG Amsterdam, Netherlands

3 ICLON, Leiden University, Wassenaarseweg 62A, 2333 AL Leiden, Netherlands

4 Postbus 905, 2300 AX Leiden, Netherlands 
regular instructional approach towards that of the proposed reform while taking their regular instructional approach as a starting point.

Keywords Educational reform · Intentions · Beliefs · Successful experiences · Instructional approaches

\section{Introduction}

In recent years, there has been much debate on educational reforms and their implementation in secondary education. Many educational reforms have been found to cause implementation problems, and the teachers involved have questioned the value of the proposed reform for their daily practice (Fullan 2007). Research about the implementation of educational reforms shows that teachers play a crucial role in achieving the goals of a reform (Fullan 2007; Van Driel et al. 2001). A reform proposal can therefore only succeed if teachers expand and change their behavioral repertoire in line with the reform. However, changing teachers' regular practices and routines has proven to be very difficult. For a successful behavioral change, it is not enough to simply offer teachers new knowledge and skills; they also need to be motivated to change. Literature on behavioral change shows that people need both the ability and the willingness to change their behavior successfully (Fishbein and Ajzen 2010). However, in current approaches to teacher professional development, there seems to be an emphasis on supporting teachers in their ability to change, whereas teachers' willingness to change receives too little attention (Borko et al. 2010).

In the study described in this article, we therefore explored teachers' willingness to change by focusing on intentions to change. We performed "motivating-for-educational-change" interviews (MECI) and explored the resulting developments in the strength and specificity of teachers' intentions to change in the direction of a context-based reform proposal. If successful in achieving strong intentions, the MECI could be a useful tool to administer at moments such as the start of a professional development program or when motivation to continue professionalization is lacking. The MECI technique was based on two approaches: (1) analysis and redesign of teaching practices by using lesson segments and (2) the use of teachers' earlier successful experiences with parts of the proposed reform. Both approaches are further elaborated in the theoretical framework. We explicitly focused on the strength and specificity of intentions, as these are found to be the closest determinants for the occurrence of new behavior (Fishbein and Ajzen 2010). The research took place in the Netherlands, where the National Reform Committee for Biology Education proposed a context-based reform program (Boersma et al. 2007) in secondary biology education. The research question was the following: To what extent do the strength and specificity of biology teachers' intentions to implement a context-based educational reform change when teachers are subjected to a MECI and how do the two approaches in a MECI affect the outcomes?

\section{Theoretical Framework}

One of the most important factors in the success rate of any educational reform is the way in which it is implemented. Often, the goals and vision of an educational reform are formulated by a reform committee at a rather abstract level and need to find their way into day-to-day teaching practices. However, such goals and visions of educational reforms such as increased 
student outcomes or higher student motivation are often watered down in the process of implementation (Van den Akker 2003). In the process of implementing a reform proposal, there are many actors. There is a vast amount of literature concerning the change of classroom practices that places teachers as "key agents" in attempts to change classroom practice (Ball and Forzani 2009; Borko et al. 2010; Wilson 2013). As Fullan (2007) stated: "Educational change depends on what teachers do and think-it's as simple and as complex as that" (p. 129).

In the implementation of any educational reform, it is therefore important that teachers expand their behavioral repertoire on the basis of the reform requirements. In the field of social psychology, there is a wide consensus on the conditions for effective behavioral change. Three major conditions are considered to be necessary for any new behavior to occur (Fishbein and Ajzen 2010):

1. An individual has to have the knowledge and skills necessary to perform the new behavior.

2. The environment must support the occurrence of the behavior.

3. An individual has formed a strong positive intention to perform the new behavior.

In many of the current approaches to teacher professional development in the context of implementing educational reform, there is a strong emphasis on the first condition (Loucks-Horsley et al. 2010; Wilson 2013). In such an approach, there is attention to the development of knowledge that teachers need to implement a reform (Borko et al. 2010). Also, in recent years, the notion has sprung up that teachers need to develop the skills necessary to be capable of implementing the change proposal (Ball and Forzani 2009; Grossman et al. 2009). In regard to the second condition, some of the existing approaches also pay attention to the limited availability of time, possibilities, and resources that teachers have for changing their behavior (Doyle 2006; Kennedy 2010). However, the third condition, the formation of a strong intention to change, is explicitly lacking in many attempts to implement a reform proposal. This formation of strong intentions to change behavior, however, may well be a crucial step in the process of implementing a reform proposal into corresponding classroom behavior.

In their influential work on understanding intentions, Fishbein and Ajzen (2010) state that intentions can be defined as the readiness to perform a certain behavior or an indicator of how hard people are willing to try to perform the behavior. The stronger the intention, the more likely it is that the goal behavior will be carried out. In their theory of planned behavior, Fishbein and Ajzen (2010) state that three kinds of beliefs serve to determine the strength of an intention:

(a) Behavioral beliefs: positive or negative consequences people might experience if they performed the goal behavior. Together, these beliefs are responsible for a positive or negative attitude.

(b) Normative beliefs: beliefs about the approval or disapproval of important groups or persons on the execution of the goal behavior. These beliefs are responsible for the perceived social pressure to engage or not to engage in the behavior.

(c) Control beliefs: factors that help or hinder the attempt to carry out the goal behavior. These beliefs constitute the perceived behavioral control and are thought to be closely related to Bandura's $(1977,1997)$ well-known concept of self-efficacy . 
What follows from the above is that if there are many factors that hinder attempts to carry out the behavior (control beliefs), many expected disadvantages of the outcomes (behavioral beliefs), and low social support (normative beliefs), the strength of an intention will be lowered, and vice versa. Beliefs about certain goal behavior have been studied extensively in educational research (see Pajares 1992). Such belief studies are, however, mainly focused on general educational beliefs about, e.g., teaching and learning, or teachers' epistemology (Boulton-Lewis et al. 2001; Schommer 1990). In recent years, there has been a call for more domain-specific beliefs, belief studies that are as teachers' orientations towards specific topics (Van Driel, Bulte, and Verloop 2007). But even in such more domain-specific belief studies, a straightforward relationship between the beliefs and the actual practice of teaching seems to be lacking (Ajzen and Fishbein 2005; Richardson 1996; Stipek 2001). In the present research we propose that this gap between teachers' beliefs and concrete teaching practices can be bridged by using intentions as proposed by Fishbein and Ajzen (2010). These intentions, are underpinned by beliefs (see Fig. 1), but are also closely related to the actual behavior. In fact, the strength of intentions is known to predict the occurrence of specific behavior (Fishbein and Ajzen 2010).

It is, however, not solely the strength of an intention that determines the likelihood of new behavior occurring. People can have strong intentions but not act on upon them (Orbell and Sheeran 2000). In his work analyzing this discrepancy between intentions and behavior, Gollwitzer (1999) tried to narrow the gap between intentions and behavior. He found that goals formulated in intentions are more easily attained when intentions are more specific about the how, when, and where. This measure of specificity could well be the complementing factor needed to fully understand how intentions influence behavior.

The theory of planned behavior has been used extensively to predict behavior in many fields of society, such as health care (donating blood) and political behavior (voting choice) (Fishbein and Ajzen 2010). In such research, interviews are performed that serve as a basis for questionnaires in which participants report on their beliefs to engage in specific behavior (e.g., running, attending classes, losing weight), which together predict the strength of the intention to actually perform that behavior (Fishbein and Ajzen 2010). Although we make use of

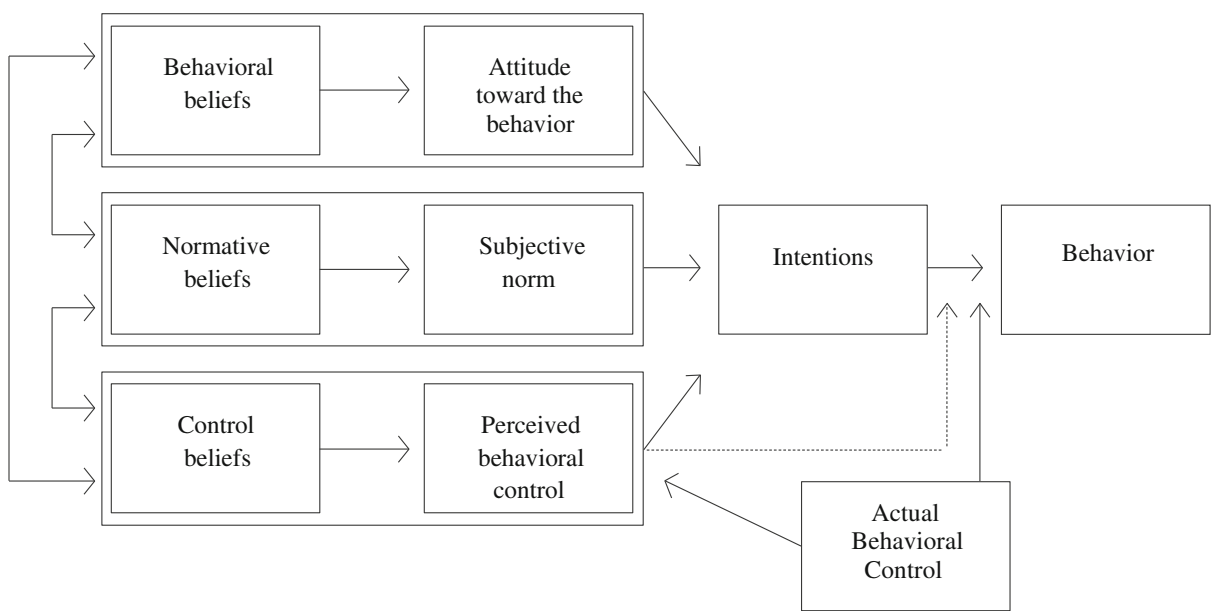

Fig. 1 Graphical representation of the theory of planned behavior. Behavior is influenced by intentions, which in turn are underpinned by three categories of beliefs (Fishbein and Ajzen 2010) 
interviews and the theory of planned behavior, the purposes of interviews in this article are rather different. The interviews presented in this article are not primarily designed to collect data or report on change but to stimulate strong and specific intentions for change. A conventional interview technique that includes interview questions regarding participants' thoughts about a certain change proposal and/or questions about the extent to which a participant intends to perform a proposed change (intentions) is not suitable for a number of reasons. Primarily, it may be hard for participants to estimate how a change proposal works out in their specific situations. Next, it may also be difficult for them to estimate how their current situation relates to the proposed change. What follows from such difficulties is that for participants, it can be hard to estimate how a change proposal affects their existing beliefs, current behavior, and, in this specific study, students' behavior alike. Finally, not knowing how a change proposal works out in one's specific situation and not knowing the effects of implementing change on one's beliefs, current behavior, and student behavior are not likely to result in strong and specific intentions.

With that in mind, we can formulate certain conditions for an interview technique that motivates for change by stimulating the formation of strong and specific intentions. The first condition is that participants should be enabled to understand the proposed change, which in this study involves introducing a context-based reform, in such a manner that they understand how this works out in their specific situation, which in this study is the classroom level. If the reform is represented in the same terminology and level of abstraction of their regular classroom practice, both understanding and comparison of the proposed change and the existing situation are made possible. For this, we present the concept of lesson segments, which are phases of single lessons such as explaining, reflecting, or presenting a context. The second condition is that participants are enabled to understand the consequences of changing their existing classroom practice. For this, we ask participants to explicate previous experiences with aspects of the goal behavior. More specifically, we ask participants to think back to earlier successful experiences with the goal behavior or parts of the goal behavior. If teachers can be made aware that they already executed parts of the desired behavior successfully in earlier settings, we hypothesize that they will be able to see the positive consequences of this behavior in new settings, which in turn might affect their beliefs, leading to the formulation of strong intentions. In the next sections, we will further elaborate these conditions into two approaches used in a MECI.

\section{Using Lesson Segments to Rearrange Instructional Approaches}

From the literature, it is known that the strength of an intention to perform acertain new behavior depends for a large part on how much the individual in question values the goal situation as an improvement (Pollock 2006). In order to judge whether a proposed goal situation is an improvement, one has to be able to compare the existing and goal situations (Simon 1978). However, this is often not possible due to different terminology or levels of abstraction of the two situations. In educational settings, the change proposal (goal behavior) is usually formulated as a vision or rationale instead of a program for practice. Such visions conflict with the practices of many teachers, which are very specific and concrete about how to act. This situation asks for a tool in which both existing teaching practices and the proposed reform can be represented at the same level of abstraction and in the same terminology. To construct such a tool, we made use of the work of Holland (2000), who states that most, if not all, innovations can be understood as the rearrangement of the smaller parts or building blocks that make up a certain structure. Holland (2000) argues that in order to propose an innovation, one first needs to find the essential building 
blocks within a certain environment and, next, arrange them differently to propose innovation. Translated to education, this implies that educational innovation can be reached by rearranging the main building blocks of educational settings (Janssen et al. 2015). These building blocks should be focused on the most effective elements of education that directly influence student learning. Research by Merrill (2001) and Merrill et al. (2008) showed that these most effective parts of classroom education are the main teaching-learning activities such as presenting, practice, or giving demonstrations. In our research, we therefore determined the building blocks to be segments of lessons that constitute lessons, as teachers teach many every day. Put in specific orders, such lesson segments can then represent a variety of instructional approaches. In our research, we made use of lesson segments in the setting where teachers have to learn to shift their practices towards the reform requirements. Lesson segments could serve as a tool to (1) represent teachers' regular practices, (2) represent the change proposal at classroom level, (3) make comparison possible, and (4) facilitate teachers' to recombination or adaption of the lesson segments of their regular teaching practice to change in the direction of the change proposal. This concept of lesson segments has been used in previous research by the authors and others (Dam et al. 2013; Janssen et al. 2015). Elaboration of the actual lesson segments for the present study is described in the "Methods" section.

\section{Building on Earlier Successful Experiences}

The second approach in the MECI is structured around the use of teachers' earlier successful experiences with the goal behavior or parts of the goal behavior. If teachers think back to successful experiences, they can see that they have already performed the goal behavior, or parts of it, successfully in the past. This implies that the use of earlier successful experiences could also help teachers to think back to the benefits of their execution of that behavior in the past, which in turn could positively influence the strength and/or specificity of their intentions and their behavioral beliefs for future behavior.

The idea of working with successful experiences is derived from the field of psychology, where Seligman and Csikszentmihalyi (2000) emphasized that "treatment is not just fixing what is broken; it is nurturing what is best" (p. 7). Central to this positive approach is helping people to use their positive qualities and strengths of character for personal growth and change. On the basis of the same idea, psychotherapists in the early 1980s worked on a new method for helping patients to tackle problems (De Shazer 1985; Miller et al. 1996). Their approach focused directly on patients' skills and goals instead of an in-depth analysis of patients' problems. Patients first stated what goals they wished to achieve, followed by a check whether they had ever actually realized these goals in previous settings (i.e., finding positive exceptions in the past in which the desired behavior was already present). These sometimes small, positive exceptions were rephrased into solutions for the patients to solve their problems and achieve their goals. In short, this approach focuses on solutions instead of problems and aims to build on earlier successful experiences with the goal behavior, or sometimes parts thereof Translating this approach to the field of education, Janssen, De Hullu, \& Tigelaar (2008) found that preservice teachers' reflection on successful experiences led to stronger intentions and more positive beliefs than when they reflected on problematic experiences. In this study, teachers were explicitly asked to think back to earlier successful experiences with parts of the goal behavior, that is, teaching according to the context-based curriculum proposal. For this, we made use of standard solution-focused questions like: Did you ever have positive experiences with contextbased education or parts of context-based education? and When you compare your regular 
teaching practice to context-based education, can you think of anything that could take your regular behavior one step towards context-based education?

The MECI technique thus comprised two approaches, i.e., building on successful experiences with aspects of the goal behavior and using lesson segments to rearrange lesson structures and make sense of a specific innovation. Combining these tools was hypothesized to positively influence both the strength and specificity of biology teachers' intentions to make a change towards the proposed context-based reform. Interviews in general mainly serve as a source of information and questions that are intended to be unbiased. The MECI in this study is, however, developed to affect teachers' thinking and is therefore biased.

\section{The Introduction of a Context-Based Curriculum}

This research took place in the setting of introducing a context-based curriculum proposal in secondary biology education in the Netherlands. A National Reform Committee for Biology Education (CVBO) proposed a context-based curriculum (Boersma et al. 2007) that was designed to increase the relevance and coherence of the curriculum and reduce the curriculum overload. The aim was to achieve appealing curricula in which the subject matter is taught and organized through contexts. Context-based education is characterized by the use of a context that is relevant to students so that they can feel relate to. Students are encouraged to direct their own learning process and work around a central question or problem that arises from the context, and then reflect on the outcomes and the learning process (Bennett et al. 2007; Bennett et al. 2005; Boersma, 2011; Bulte et al. 2006). The underlying idea of this contextbased curriculum is that students will learn to direct their own learning and come to see the important role of biology in society and further education. The use of a context in education is thought to increase relevance, coherence, and meaning for students (Gilbert 2006). As the aim for contexts in the proposed reform is to be culturally defined and realistic, the reform committee has proposed three categories for these contexts: professional, academic, and the public sphere (Boersma et al. 2007). In the Netherlands, government policy states that educational policy makers can prescribe certain content and final requirements, but not specific teaching methods. Teachers in secondary education thus have a great deal of autonomy. The reform committee therefore focused on updating the biological subject matter of the curriculum and on the formulation of new objectives and final requirements. However, meeting these new objectives and requirements will inevitably have pedagogical implications for biology teachers. Bridging the gap between the rather abstract reform proposal and the actual enactment in classrooms was an important motive for this study. The MECI technique in this study was administered at the moment of the nationwide introduction of the context-based curriculum.

\section{Methods}

\section{Selection of Participants}

The introduction of a context-based curriculum with subsequent didactical implications is meant for all biology teachers at the secondary level in the Netherlands. Therefore, participants needed to be selected to vary in terms of characteristics such as teaching experience, experience with context-based education, gender, and grade level. We consulted two experts with a wide 
network of biology teachers, and after invitations to specific teachers were sent, six biology teachers from six different secondary schools in the west of the Netherlands enlisted for this research, which had a qualitative design using case studies. Three of these teachers had colleagues who also wanted to participate in this research, so they were also included as participants. The final nine participating teachers (five female, four male) had a wide range of teaching experience and taught upper- and/or lower-level classes in general secondary or pre-university education, and only Ryan and Howard had experience with context-based education (see Table 1).

\section{Lesson Segments}

The lesson segments in this study were designed as a tool to bridge the perceived gap between a teacher's regular practice and the change proposal for biology education, that is, the introduction of a context-based curriculum. By rearranging and/or adapting one or more lesson segments, teachers were given a tool to propose a change in the direction of the proposed reform. We chose to base the lesson segments on the work of Merrill (2001), who proposed four lesson segments to design different forms of direct instruction (tell, show, ask, and do). However, we also needed to add lesson segments that enabled the design of context-based teaching practices. For this, we looked into the characteristics of context-based education, e.g., starting with a context with a central question.

The teachers' regular practice served as a starting point for change (e.g., explain-type questions to recall and/or apply-type questions). Next, the teachers were asked to propose an intention stating how they wanted to change their regular practice in the direction of the reform. For this, the lesson segments that constituted context-based education were presented to them and they were asked in what way they could rearrange or adapt the lesson segments that constitute their regular practice to approach context-based education. For the complete set of lesson segments used in this research, see Table 2.

\section{Procedure}

When constructing the MECI protocol, we first trialled the interviews with four secondary school biology teachers (pre-university education $n=3$, general secondary education $n=1$ )

Table 1 Details of participants

\begin{tabular}{llllll}
\hline Participant & Age & $\begin{array}{l}\text { Teaching } \\
\text { experience (years) }\end{array}$ & $\begin{array}{l}\text { Experience with context- } \\
\text { based education (years) }\end{array}$ & Grade level & $\begin{array}{l}\text { Upper/lower } \\
\text { secondary level }\end{array}$ \\
\hline Walter & 40 & 10 & 0 & PUE & Higher \\
Anne & 52 & 4 & 0 & GSE & Lower \\
Ryan & 34 & 5 & 4 & PUE & Higher \\
Kathryn & 49 & 12 & 0 & PUE & Higher \\
Howard & 49 & 11 & 3 & PUE & Higher \\
Becky & 46 & 10 & 0 & GSE & Lower \\
Mark & 28 & 3 & 0 & GSE & Higher \\
Julia & 47 & 10 & 0 & GSE & Higher \\
Ivy & 42 & 10 & 0 & PUE & Higher \\
\hline
\end{tabular}

$P U E$ pre-university education, GSE general secondary education 
Table 2 Survey of lesson segments used in this research

\begin{tabular}{ll}
\hline Lesson segment & Definition \\
\hline Orienting & $\begin{array}{c}\text { Introducing the subject, formulating goals, activating prior knowledge, and } \\
\text { planning time and activities } \\
\text { Testing }\end{array}$ \\
$\begin{array}{l}\text { Assessing to what extent the learning outcomes and/or processes match the } \\
\text { pre-set goals } \\
\text { Reflecting }\end{array}$ & $\begin{array}{c}\text { Looking back on results or processes, finding explanations for success or } \\
\text { failure, finding improvements }\end{array}$ \\
$\begin{array}{l}\text { Explaining } \\
\text { Introducing context with a } \\
\text { central question }\end{array}$ & $\begin{array}{c}\text { Introducing the context with an attendant central question or problem } \\
\text { Recalling and/or applying }\end{array}$ \\
& $\begin{array}{c}\text { Recalling: assigning questions or tasks for which knowledge or skills learned } \\
\text { earlier have to be literally repeated }\end{array}$ \\
& $\begin{array}{c}\text { Applying: assigning questions or tasks in which knowledge acquired earlier } \\
\text { has to be applied in new settings }\end{array}$ \\
Answering questions & Answering the question or questions
\end{tabular}

and asked them to provide feedback on issues such as language use, practicality of the lesson segments, and utility of the MECI. Based on this, we adapted the interview protocol with regards to the order and phrasing of the questions.

Before administering the MECI, we first conducted a baseline test $(t=0)$ in which we introduced the participating teachers to the reform using official reports published by the reform committee. These reports are the main source of information related to this education reform for any biology teacher in the Netherlands. In this baseline test, the teachers were asked how they would naturally implement context-based education in their own teaching practice based on reading the official reports. Next, this was formulated as an intention to change. The teachers then indicated the strength of the intention on a Likert scale ( $1=$ weak to $7=$ very strong).

After this, we conducted the MECI. In the following, we will briefly explain the main steps of the protocol (for precise questioning and order, please see the Appendix). The interviewer first asked participants to describe their regular teaching practices. We then asked participants to represent the same regular teaching practice in the given lesson segments. When the meaning of a lesson segment was unclear from the list (see Table 2), the interviewer gave additional explanation. After this, the interviewer presented the following two representations of context-based lesson structures to the participants: (1) context with a central questionanswering questions-explain and (2) context with a central question-explain-answering questions. Next, the interviewer asked questions to elicit earlier successful experiences with parts of context-based education, for example, (Have you ever had positive experiences with either form of the presented sequence of context-based education or aspects of context-based education, and if so, why was this successful?.

The intention to change was calculated from the answers to the following open question in the MECI: What could take your regular teaching practice one step towards the goal situation? After collecting the intentions, teachers were asked to indicate the strength of their new intentions on a Likert scale ( $1=$ weak to $7=$ very strong). This method of rating intentions was previously described by Fishbein and Ajzen (2010). The final step was to elicit specific beliefs about the new intention or intentions. We therefore posed questions on behavioral beliefs (advantages and disadvantages), normative beliefs (people that approve or disapprove), and control beliefs 
(enabling and hindering factors). Each MECI lasted between 1.75 and 2 hours and were recorded using voice recording technology.

\section{Data Gathering and Analysis}

To determine the development of the strength and specificity of biology teachers' intentions, we gathered several data. First, we gathered all the intentions and their strengths, both from the baseline test and those expressed during the MECI. We also listened to the recorded interviews to transcribe the exact phrasing of the intentions in order to determine the specificity of an intention. This specificity of intentions was then determined by analyzing to what extent an intention is specific about the how, when, and where (Gollwitzer 1999). There was a clear goal for the participants, i.e., the two sequences of lesson segments that represent context-based education. This restricted the formulation of intentions, so that in fact all intentions were aimed at the goals of the context-based reform. However, as shown in the MECI protocol (Appendix, Questions 3 and 4 in Table 4), the questions gave the participants the possibility to individually determine the aspect or aspects of context-based education they were most motivated for.

To understand how the two approaches in a MECI affect the outcomes, we analyzed their specific roles during the interview and looked into the underlying beliefs of the intentions. We expected that earlier successful experiences helped the teachers to think back to situations where they were able to execute the required behavior and see the benefits of the goal behavior. We expected the set of lesson segments to assist the teachers in recombining and adapting their regular teaching practice in order to propose a change towards the goal situation, in this study being context-based education. On the basis of these hypothesized outcomes, we specifically looked into data from the interview recordings where the teachers spoke about (a) earlier successful experiences, (b) their regular practice and the sequence of lesson segments that represents it, (c) the rearrangement or adaptation of the sequence or content of lesson segments, and (d) beliefs about intentions. For each participant, we made a document with an overview of these data, which was then sent back to the participant for a member check to ensure internal validity (Miles and Huberman 1994). After all the teachers had approved the documents as good representations of the interview, the first and second authors further analyzed the data. We first checked whether intentions were formulated in terms of rearranging and/or adapting lesson segments. Also, did teachers refer to specific successful experiences when formulating intentions to change? If so, were these successful experiences helpful in predicting hindering and enabling factors, advantages and disadvantages, and/or people that approve or disapprove due to the fact that they already executed the required behavior?

\section{Results}

There were several distinctive outcomes in this study. Regarding the changes in the strength and specificity of teachers' intentions, the first thing to note is that, compared to the baseline test, all the teachers scored the strength of their intentions higher when subjected to the MECI (see Table 3). Important here is that intentions formulated in the baseline test $(t=0)$ are often qualitatively different from those formulated within the MECI. Comparison of the intentions also showed that the teachers formulated more intentions compared to the baseline test.

A second result of the MECI technique is that it indeed resulted in intentions that are more specific than those found in the baseline test. Mark, for example, first formulated an intention 
in which he wanted to connect student activities to the topic within a context. During the MECI, however, he formulated an intention in which he wanted to start the lesson using a context and work from examples and movies he had already used in previous classes. Another participant, Anne, formulated the following intention in the baseline test: "I want to do something with pupils' prior knowledge by constructing something together." During the MECI, she was able to be more specific in the how: "I want to start the lessons by using a context" and "I want the pupils to be actively searching for information to answer the central question."

As to the roles of the two approaches in the MECI, i.e., building on successful experiences and using lesson segments, it seems that each functioned to assist teachers in specific ways. First, teachers were indeed able to represent their regular teaching practice in a specific sequence of lesson segments, which made comparison with the sequences of context-based education possible. Such an instrumental comparison enabled the participants to realize that sometimes they had already implemented a certain part of context-based education in their regular practices. For example, the participants recognized that they already used larger examples or application exercises in which the students had to find an answer to certain problems by themselves. However, they would normally assign such exercises or tasks later on in their lessons. In this study, they arranged lesson segments differently and shifted the lesson segment "context with central question" to the start of a lesson. In Julia's own words: "I would like to start the lesson with a context, for which I will use application exercises that I normally hand out later in the lesson" (Table 3) or Mark's words: "I want to start the lesson with a context, working from the examples and movies I normally show separately" (Table 3). Knowing how to design and introduce a context, even in a small variant, stimulated feelings of ability (control beliefs), as further illustrated in the case studies below. Second, teachers were also able to use the terminology of the lesson segments in formulating intentions, which implies that seeing the reform represented in lesson segments helped them to devise ways in which they could change towards the reform. Third, when asked about earlier successful experiences, all the participants were able to think back to relevant successful experiences with parts of the proposed reform. Doing so, they envisioned situations in which they had already successfully implemented parts of the reform from which they were able to predict the specific advantages and disadvantages (behavioral beliefs) of how this had worked in those situations. This also seemed to lead to high feelings of control (control beliefs), as these experiences were successful. In the remainder of this section, we will describe two cases of participating teachers in which we try to visualize the process and outcomes of the MECI technique and the way in which the teachers' intentions interrelate to certain beliefs. We selected Walter because of his interesting attitude of not seeing the benefits of the reform and Mark because he is a younger teacher who is willing but has little experience that he can draw on. Both of these participants were not previously trained or educated in introducing a context-based reform such as the one reported in this article.

\section{The Case of Walter}

Walter is a 40-year-old biology teacher with 10 years of teaching experience. He is an enthusiastic biologist with a huge private collection of bird skeletons who likes to convey his passion for biology to the students. His reasons for participation in our research were his curiosity about what the context-based reform proposal would mean for his everyday practice and the opportunity to expand his teaching repertoire in a broader sense. His most 
Table 3 Survey of intentions in the baseline test and the MECI

\begin{tabular}{|c|c|c|c|c|}
\hline \multirow[t]{2}{*}{ Name } & \multicolumn{2}{|l|}{ Baseline test $(t=0)$} & \multicolumn{2}{|l|}{ Formulated in the MECI } \\
\hline & Intentions & Strength & Intentions & Strength \\
\hline Walter & $\begin{array}{l}\text { I want to choose a subject that is spread } \\
\text { over several chapters of the textbook } \\
\text { and teach this in a more coherent way. }\end{array}$ & 3.5 & $\begin{array}{l}\text { I want to start the lesson with an } \\
\text { example or situation, which I } \\
\text { normally plan at the end of the } \\
\text { lesson. From this example, I will } \\
\text { formulate central questions for the } \\
\text { pupils. After that, I will explain the } \\
\text { topic and give notes. With this } \\
\text { explanation and the textbook, pupils } \\
\text { will have to answer the central } \\
\text { questions. }\end{array}$ & 6.5 \\
\hline \multirow[t]{2}{*}{ Anne } & $\begin{array}{l}\text { I want to do something with the pupils' } \\
\text { prior knowledge by constructing } \\
\text { something together. }\end{array}$ & 5 & $\begin{array}{l}\text { I want pupils to be actively searching } \\
\text { for information to answer the central } \\
\text { question. }\end{array}$ & 7 \\
\hline & & & $\begin{array}{l}\text { I want to start the lessons by using a } \\
\text { context. }\end{array}$ & 7 \\
\hline \multirow[t]{3}{*}{ Ryan } & $\begin{array}{l}\text { I want to be able to help students to } \\
\text { learn specific contents. }\end{array}$ & 5.5 & $\begin{array}{l}\text { I want the pupils to look for and find the } \\
\text { required specific knowledge } \\
\text { themselves on the basis of specific } \\
\text { questions. }\end{array}$ & 6 \\
\hline & & & $\begin{array}{l}\text { I want to start the lesson with a context } \\
\text { more often. }\end{array}$ & 6 \\
\hline & & & $\begin{array}{l}\text { I want to use more student-centered } \\
\text { activities. }\end{array}$ & 6 \\
\hline \multirow[t]{3}{*}{ Kathryn } & $\begin{array}{l}\text { I want to start the lesson by presenting a } \\
\text { context. }\end{array}$ & 6 & $\begin{array}{l}\text { I want to start the lesson by presenting a } \\
\text { context followed by a central } \\
\text { question. }\end{array}$ & 7 \\
\hline & & & $\begin{array}{l}\text { I want to give pupils a more prominent } \\
\text { role in reflecting on the lesson. }\end{array}$ & 7 \\
\hline & & & $\begin{array}{l}\text { I want to demonstrate first how to } \\
\text { answer questions. }\end{array}$ & 7 \\
\hline \multirow[t]{2}{*}{ Howard } & $\begin{array}{l}\text { I want to focus the lesson on the } \\
\text { concepts to be learned. }\end{array}$ & 6 & $\begin{array}{l}\text { I want to use a context to motivate } \\
\text { students for practical work in the } \\
\text { next week. }\end{array}$ & 6 \\
\hline & & & $\begin{array}{l}\text { I want students to be involved in } \\
\text { designing contexts. }\end{array}$ & 6.5 \\
\hline Becky & $\begin{array}{l}\text { I want to start the lesson by presenting a } \\
\text { context. }\end{array}$ & 6 & $\begin{array}{l}\text { I want to construct contexts from the } \\
\text { questions that pupils asked in earlier } \\
\text { lessons. After that, I want the pupils } \\
\text { to answer the questions themselves. }\end{array}$ & 7 \\
\hline \multirow[t]{3}{*}{ Mark } & $\begin{array}{l}\text { I want to connect student activities to } \\
\text { the subject within a context. }\end{array}$ & 4 & $\begin{array}{l}\text { I want to start the lesson with a context, } \\
\text { working from the examples and } \\
\text { movies I normally show separately. }\end{array}$ & 6 \\
\hline & & & $\begin{array}{l}\text { I want to pose a central question that } \\
\text { follows from the context and have } \\
\text { students find the answers. }\end{array}$ & 4 \\
\hline & & & $\begin{array}{l}\text { I want students to work in small groups } \\
\text { on solving the central questions. }\end{array}$ & 4 \\
\hline Julia & None & - & $\begin{array}{l}\text { I would like to start the lesson with a } \\
\text { context, for which I will use }\end{array}$ & 5.5 \\
\hline
\end{tabular}


Table 3 (continued)

\begin{tabular}{|c|c|c|c|c|}
\hline \multirow[t]{2}{*}{ Name } & \multicolumn{2}{|l|}{ Baseline test $(t=0)$} & \multicolumn{2}{|l|}{ Formulated in the MECI } \\
\hline & Intentions & Strength & Intentions & Strength \\
\hline \multirow{3}{*}{ Ivy } & \multirow{3}{*}{$\begin{array}{l}\text { I want to have pupils work together on a } \\
\text { certain problem within a context. }\end{array}$} & \multirow{3}{*}{6.5} & $\begin{array}{l}\text { application exercises that I normally } \\
\text { hand out later in the lesson. }\end{array}$ & \\
\hline & & & $\begin{array}{l}\text { I want to start the lesson by presenting a } \\
\text { context, for which I will use adapted } \\
\text { assignments that I would normally } \\
\text { hand out after the explanation phase. }\end{array}$ & 6.5 \\
\hline & & & $\begin{array}{l}\text { I want the pupils to look up and find the } \\
\text { required information themselves. }\end{array}$ & 6.5 \\
\hline
\end{tabular}

Rated on a Likert scale $(1=$ low and $7=$ high $)$

common approach to instruction is to present biological topics in a traditional classroom setting. He really feels that he has to emphasize the most important terms from the textbook and show the students how these relate together. In his lessons (50 minutes) he regularly lecture most of the time and has the students do recall (sometimes application) exercises for the last 10 minutes of the lesson. He is not very enthusiastic about the reform proposal. In the baseline test, Walter mentioned that he had read the official reports published by the National Reform Committee and that he recognized the notion about little curricular coherence in his own teaching practice. Because of this, he formulated the following intention in the baseline test: "I want to choose a subject that is spread over several chapters of the textbook and teach this in a more coherent way." He rated the strength of this intention 3.5 [I think this scale has been sufficiently introduced previously.] In the subsequent interview, he represented his regular teaching practice in the following lesson segments: orientation-explain-reflect-recall and/or apply-answering questions.

During the MECI, the interviewer showed the context-based lesson sequences (goal situation), represented by the same set of lesson segments (see "Methods" section). We then asked Walter whether he had ever had a successful experience related to the goal behavior. He stated that he had already tried to engage pupils by using examples from pupils' everyday lives, for examples by presenting the ADH hormone in relation to the maximum amount of alcoholic drinks on a night out. He also had had some experience with teaching thematic units and at that time had found pupils to be active learners. However, pupils had also said to him that he could explain subjects really well and that his notes were excellent and helpful. He stressed the importance of giving notes and the central role of the textbook in his lessons. However, he also admitted that students were more engaged and concentrated more when he asked them an interesting question, for instance, about the role of the liver in the breakdown of alcohol. After reflecting on such examples, he exclaimed: "So if the reform program proposes a context to engage and motivate students to find information themselves, this means that I sometimes already apply part of the reform within my regular lessons?" On the basis of his successful experiences, he formulated the following intention to change his lesson sequence in line with context-based education: "I want to start the lesson with an example or situation, which I normally plan at the end of the lesson. From this example I will formulate central questions for the pupils. After that, I will explain the topic and give notes. With this explanation and the textbook pupils will have to answer the central questions." The strength of this intention was 6.5. 
Next, we asked questions concerning his beliefs about this intention. As behavioral beliefs (advantages and disadvantages), he mentioned that he saw advantages in creating increased relevance for the students by connecting to the students' experiences in the context, in the idea that he could still explain the topic at hand before the phase of finding answers, and in the idea of being able to use students' questions in his explanation. As disadvantages, he expected a slower pace throughout the lessons and students' negative reactions to their changing roles. As normative beliefs (people that approve or disapprove), he mentioned no persons or groups in particular that he thought would approve or disapprove. As control beliefs (enabling and hindering factors), he mentioned the limiting aspects of not having enough time to let students find the necessary information themselves, the fact that not all information needed to solve a task can be found in the students' textbooks, and the fact that not all topics are suitable for starting with a context because sometimes the necessary pre-existing knowledge is lacking. Finally, he considered an enabling factor to be the fact that he already had some experience within a thematic unit in which he started the lesson series with an example from everyday life.

\section{The Case of Mark}

Mark is a 28-year-old teacher with only three years of experience who loves the interaction with students but feels that he has a lot to learn as a teacher. He was educated at the bachelor level and was teaching upper secondary level for the first year at the time of the MECI. He is very creative in finding the interesting and funny sides of biological subjects in media and books. He formulated the following intention in the baseline test: "I want to connect student activities to the subject within a context." He rated the strength of this intention 4 . In the following interview, he represented his regular teaching practice in the following lesson segments: explain-test and/or reflect-recall-context with central questions-answering questions. When comparing this regular teaching practice to the sequences of context-based education, he mentioned that he sometimes used a short video or news article to let the students calm down after entering his classroom or at the end of his lessons to fill up some time. However, he did not connect these to the learning goals or the subject at hand. He also had good experiences in solving problems together with the students.

Based on these successful experiences, he formulated several intentions for the long and short term. Here, we only mention the short-term intention: "I want to start the lesson with a context, working from the examples and movies I normally show separately." $\mathrm{He}$ rated the strength of this intention 6. As advantages, he mentioned that he expected students to be positively surprised by starting with a context. Also, he expected students to be more motivated and actively involved in finding answers for the attendant problems and questions. Disadvantages would be his idleness - he liked the idea of being listened to - and his desire to please students in what they want. People that agree would be the school board members and his colleagues. His concerns for people who disagree relate to the parents who cannot control what is learned when he starts to teach topics outside the textbook. As an enabling factor, he mentioned that he already showed examples and movies, which means that connecting these to the subject is only a small step. Further enabling factors are his talent in designing contexts with attendant questions that are relevant to the students and his progressiveness in using ICT in the classroom. As factors that might hinder, Mark mentioned extra preparation time, the textbook with its focus on exercises to recall information, and the school climate, where in most lessons, the majority of the students are used to sitting back and listening to their teachers. 


\section{Conclusions and Implications}

Professional development aimed at the implementation of an educational change proposal often focuses on the skills and knowledge that teachers need to improve and/or changes in the environment in which they work. However, formulating strong intentions to change is often not included in professional development programs (Fishbein and Ajzen 2010). In this article, we reported on our research into the changes of teachers' intentions to change in the direction of context-based biology education when using a "motivating-for-educational-change" interview (MECI). The results show that intentions to change were positively influenced by the MECI technique. When subjected to a MECI, all participating teachers formulated intentions that were stronger than those in the baseline test (see Table 3). The intentions were also found to be more specific in their description of how to enact the reform, and eight out of nine teachers also formulated more intentions to change. The ninth teacher (Julia) could not think of any intention to change her teaching behavior in the baseline test, but was able to formulate in what way she wanted to change when subjected to the MECI.

Both MECI tools seem to have contributed to the results, with a partial overlap. The first tool was explicitly intended for teachers to look back on past successful teaching experiences. From the literature, we expected that successful experiences would positively influence both control and behavioral beliefs. Unfortunately, comparing beliefs with those in the baseline test was not possible, as we did not measure beliefs in the baseline test. Measuring beliefs in both phases is a recommendation for future research. However, data show that thinking back to earlier successful experiences resulted in positive beliefs about the new behavior in several ways. For example, the participants thought back to earlier successful experiences, such as working around stories from cancer patients (Ivy), to understand in what way the reform would affect both their teaching practice and their materials. The teachers also discovered personal strengths, such as talent to design relevant contexts (Mark), that they used to formulate intentions to change. Interestingly, data from the case studies also imply that this process of thinking back to earlier successful experiences for future use does not require extensive teaching experience, as not only Walter but also Mark showed his ability to do so. Thinking back to situations in which the participants already successfully enacted parts of the reform, they generally saw the direct benefits for their students (positive control beliefs) and possible ways to implement the reform (control beliefs). However, they also mentioned limiting factors (control beliefs) of the proposed reform such as extra preparation time, a lack of creativity in designing contexts, or problems with directing students towards the scheduled topic. The second tool in the MECI technique was the use of lesson segments to rearrange lesson structures. Our expectation for this tool was that it would enable teachers to better compare their regular practices with context-based education and understand how to reach that reform by rearranging and adapting their regular practices. The results show that the teachers were able to formulate an intention to change towards the reform proposal in terms of rearranging or adapting lesson segments. This is illustrated in the following intention, formulated by Anne: "I want pupils to be actively searching for information to answer the central question," whereas in the baseline test she had stated that she "wanted to do something with the pupils' prior knowledge." When asked to describe their regular practice, all participating teachers reported that they normally design a lesson with questions to recall or apply information at the end. When subjected to the MECI, eight of the nine participants in our sample extended such exercises into a context and moved that lesson segment to the start of the lesson. In this way, the participants made an important step towards the essence of the proposed reform, i.e., increasing the appeal of biology by teaching and organizing subject matter through contexts. 
True and meaningful change, however, can be hard to accomplish. This is especially true for educational settings, where teachers have so many targets, responsibilities, and students and so little time, income, and mandate. As Hargreaves and Fink (2006) wrote: "Change in education is easy to propose, hard to implement, and extraordinarily difficult to sustain" (p. 6). We are aware of the limitations of this study, such as the limits to generalizability given the small sample. Also, we do not know how intentions will translate into drivers for change in practice. We focused on the formulation of strong and specific intentions because these are thought to be the closest determinants for the occurrence of new behavior (Fishbein and Ajzen 2010). On the one hand, we think that we narrowed the gap between intentions and actual behavior by emphasizing the participants' unique and personal factors, such us thinking back to personal earlier successful experiences and understanding how a reform might work out in the participants' personal classrooms by representing the reform in the same terminology and level of abstraction as their regular practice. On the other hand, we are aware that a gap between intentions and actual behavior may occur. The participants expressed their intentions and specific behavioral, normative, and control beliefs in an interview setting where they were asked to picture their everyday classroom situations. We do not know if and how these intentions and beliefs will remain in place after the specific setting of the interview and how the participants will act upon their intentions in classroom practice. We also want to emphasize the importance of distinguishing perceived behavioral control beliefs from actual behavioral control (see Fig. 1). The participants of this research stated their perceptions of behavioral control, but the occurrence of the actual behavior depends at least to some degree on opportunities and availability of other factors that determine the actual control, such as time, money, and cooperation with others (Fishbein and Ajzen 2010).

Coming back to literature on educational change processes, we can now see how this study relates to what is already known about educational change processes and what it can add. In educational change processes, people who design a change proposal are often different from the ones who enact it (the teachers or practitioners). It therefore follows that, there can be rather distinct perspectives on educational change processes depending on one's position on the implementation continuum, ranging from the reformers' perspective to the teachers' perspective (Doyle and Rosemartin 2012). On the one end of the continuum, the reformers' perspective mostly emphasizes the use of innovative procedures, new curriculum standards, or advanced instructional approaches and implies that professional development should increase teachers' capacity to use these. Research in regard to this perspective focuses on how teachers can best be trained to use the procedures and approaches associated with the reform according to their design and often sees teachers as obstacles to successful implementation (Davis and Krajcik 2005; Remillard 2008). The teachers' perspective of the implementation continuum, on the other hand, emphasizes teachers' professional expertise and autonomy, which may lead to creative adaptation of a reform with the risk of losing the essence. Existing approaches to reform implementation that aim to combine these two perspectives and take a mutual approach start by setting standards for the reform, followed by a check for knowledge and skills already present. Next, those that are not yet in place are offered in workshops or other training settings (Borko et al. 2010). In this study, however, we argue that such an approach needs elaboration. First, we have shown that strong intentions to implement change can be elicited by focusing not on missing knowledge or skills but on the personal strengths and successful earlier practices. The question should not be why teachers are not motivated for a reform but for what part of the reform they are motivated. We therefore propose a shift away from what teachers should be motivated for to what teachers are motivated for. Second, we propose that the concept of practicality needs more attention. Teachers have many goals and responsibilities and 
work in complex classroom settings where change will only be considered an improvement when it can be related to their daily teaching practices and earlier experiences. Within the MECI, we have shown that the concept of lesson segments can assist teachers in doing so.

By combining a set of lesson segments with a focus on earlier successful experiences, administering a MECI can be successful in stimulating strong and specific intentions to change in the direction of an educational change proposal. We recommend that the MECI be tested in other settings, for other reforms, and for other school subjects. Future research should also more explicitly focus on the developments of teachers' beliefs about a reform proposal. The results of this study, however, could inform both reform committees wanting to find ways in which teachers can be motivated to change and to find ways in which they can meet the new objectives and requirements. MECI can then be administered at key moments, such as the start of professional development programs, to determine for what part of a change proposal teachers are motivated. Next, teachers could start their development in the direction of the proposed reform on the basis of their specific intentions and beliefs gained through the MECI. In this way, teachers are guided by strong and specific intentions to change in the direction of a change proposal, which prevents failure of a reform's implementation (Fullan 2007).

\section{Compliance with ethical standards}

Funding was received from the Dutch Ministry of Education, Culture and Science.

\section{Appendix}

Table 4 The MECI protocol

Questions

1 How would you describe your regular instructional approach of a single lesson?

2 How would you represent this regular approach using the given set of lesson segments ${ }^{\mathrm{a}}$ ?

3 How you ever had positive experiences with either form of the presented sequence of context-based

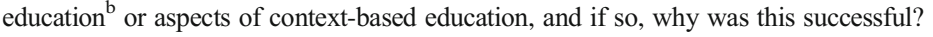

4 When you compare your regular lesson sequence to that used in context-based education, can you think of anything that could take your own regular lesson sequence (Question 1) a step towards context-based education?

5 How would you phrase the answer to Question 4 as an intention to perform certain teaching behavior in the upcoming weeks?

6 How strong is your intention on a scale from 1 to 7 ? $(1=$ weak and $7=$ strong $)$

7 What are the advantages of performing the intended behavior?

8 What are the disadvantages of performing the intended behavior?

9 Are there any individuals or groups that approve of performing the intended behavior?

10 Are there any individuals or groups that disapprove of performing the intended behavior?

11 What factors or circumstances would enable you to perform the intended behavior?

12 What factors or circumstances would make it difficult for you to perform the intended behavior?

\footnotetext{
${ }^{\text {a }}$ See Table 2

${ }^{\mathrm{b}}$ Version A: context with attendant questions-answering questions-explain; version B: context with attendant questions-explain-answering questions
} 
Open Access This article is distributed under the terms of the Creative Commons Attribution 4.0 International License (http://creativecommons.org/licenses/by/4.0/), which permits unrestricted use, distribution, and reproduction in any medium, provided you give appropriate credit to the original author(s) and the source, provide a link to the Creative Commons license, and indicate if changes were made.

\section{References}

Ajzen, I., \& Fishbein, M. (2005). The influence of attitudes on behavior. In D. Albarracín, B. T. Johnson, \& M. P. Zanna (Eds.), The handbook of attitudes (pp. 173-221). Mahwah, NJ: Lawrence Erlbaum.

Ball, D. L., \& Forzani, F. M. (2009). The work of teaching and the challenge for teacher education. Journal of Teacher Education, 60(5), 497-511.

Bandura, A. (1977). Self-efficacy: toward a unifying theory of behavioural change. Psychological Review, 84, $191-215$.

Bandura, A. (1997). Self-efficacy: the exercise of control. New York: Freeman.

Bennett, J., Grasel, C., Parchmann, I., \& Waddington, D. (2005). Context-based and conventional approaches to teaching chemistry: comparing teachers. International Journal of Science Education, 27(13), 1521-1547.

Bennett, J., Lubben, F., \& Hogarth, S. (2007). Bringing science to life: a synthesis of the research evidence on the effects of context-based and STS approaches to science teaching. Science Education, 91(3), 347-370.

Boersma, K. T. (2011). Ontwerpen van op de concept-contextbenadering gebaseerd biologieonderwijs [Designing instruction based on the concept-context approach]. Utrecht: NIBI.

Boersma, K. T., van Graft, M., Harteveld, A. L., de Hullu, E., Knecht-van Eekelen, A., Mazereeuw, M., et al. (2007). Leerlijn biologie van 4 tot 18 jaar. Uitwerking van de concept-contextbenadering tot doelstellingen voor het biologieonderwijs. Utrecht: CVBO.

Borko, H., Jacobs, J., \& Koellner, K. (2010). Contemporary approaches to teacher professional development. In E. Bekaer, B. McGaw, \& P. Peterson (Eds.), International Encyclopedia of Education (3 ed., pp. 548-555). Oxford: Elsevier Scientific Publishers.

Boulton-Lewis, G. M., Smith, D. J. H., McCrindle, A. R., Burnett, P. C., \& Campbell, K. J. (2001). Secondary teachers' conceptions of teaching and learning. Learning and Instruction, 11(1), 35-51.

Bulte, A. M. W., Westbroek, H. B., de Jong, O., \& Pilot, A. (2006). A research approach to designing chemistry education using authentic practices as contexts. International Journal of Science Education, 29(9), 10631086.

Dam, M., Janssen, F. J. J. M., \& Van Driel, J. H. (2013). Concept-context onderwijs leren ontwerpen en uitvoeren - een onderwijsvernieuwing praktisch bruikbaar maken voor docenten [Learning to design and enact context-based biology education - making an educational reform practical for teachers]. Pedagogische Studiën, 90(2), 63-77.

Davis, E. A., \& Krajcik, J. S. (2005). Designing educative curriculum materials to promote teacher learning. Educational Researcher, 34(3), 3-14.

De Shazer, S. (1985). Keys to solution in brief therapy. New York: Norton.

Doyle, W. (2006). Ecological approaches to classroom management. In C. Evertson \& C. Weinstein (Eds.), Handbook of classroom management: research, practice and contemporary issues (pp. 97-125). New York: Lawrence Erlbaum.

Doyle, W., \& Rosemartin, D. (2012). The ecology of curriculum enactment: frame and tasks narratives. Interpersonal Relationships in Education, 3, 137-147.

Fishbein, M., \& Ajzen, I. (2010). Predicting and changing behavior: the reasoned action approach. New York: Psychology Press (Taylor \& Francis).

Fullan, M. (2007). The new meaning of educational change (4th ed.). New York: Teachers College Press.

Gilbert, J. (2006). On the nature of 'context' in chemical education. International Journal of Science Education, 28(9), 957-976.

Gollwitzer, P. M. (1999). Implementation intentions: strong effects of simple plans. American Psychologist, 54(7), 493-503.

Grossman, P., Compton, C., Igra, D., Ronfeldt, M., Shanan, E., \& Williamson, P. W. (2009). Teaching practice: a cross-professional perspective. Teachers College Record, 111(9), 2055-2100.

Hargreaves, A., \& Fink, D. (2006). Sustainable leadership. San Francisco, CA: Jossey-Bass.

Holland, J. H. (2000). Emergence: from chaos to order. Oxford: Oxford University Press.

Janssen, F. J. J. M., De Hullu, E., \& Tigelaar, D. (2008). Positive experiences as input for reflection by student teachers. Teachers and Teaching: Theory and Practice, 14(2), 115-127.

Janssen, F. J. J. M., Grossman, P. \& Westbroek, H. B. (2015). Facilitating decomposition and recomposition in practice-based teacher education: The power of modularity. Teaching and Teacher Education, 51, 137-146. 
Kennedy, M. M. (2010). Attribution error and the quest for teacher quality. Educational Researcher, 39(8), 591598.

Loucks-Horsley, S., Stiles, K. E., Mundry, S., Love, N., \& Hewson, P. W. (2010). Designing professional development for teachers of science and mathematics (3rd ed.). Thousand Oaks, CA: Sage.

Merrill, M. D. (2001). Components of instruction. Toward a theoretical tool for instructional design. Instructional Science, 29, 291-310.

Merrill, M. D., Barclay, M., \& van Schaak, A. (2008). Prescriptive principles for instructional design. In J. M. Spector, M. D. Merrill, J. J. G. Van Merriënboer, \& M. F. Driscoll (Eds.), Handbook of research on educational communications and technology (3rd ed., pp. 173-184). New York: Lawrence Erlbaum.

Miles, M., \& Huberman, A. (1994). Qualitative data analysis: an expanded sourcebook. Thousand Oaks, CA: Sage.

Miller, S., Hubble, M., \& Duncan, B. (Eds.) (1996). Handbook of solution-focused brief therapy. San Francisco, CA: Josey-Bass.

Orbell, S., \& Sheeran, P. (2000). Motivational and volitional processes in action initiation: a field study of the role of implementation intentions. Journal of Applied Social Psychology, 30(4), 780-797.

Pajares, M. F. (1992). Teachers beliefs and educational research: cleaning up a messy construct. Review of Educational Research, 62(3), 307-332.

Pollock, J. L. (2006). Thinking about acting. Logical foundations for rational decision making. Oxford: Oxford University Press.

Remillard, J. T. (2008). Considering what we know about the relationship between teachers and curriculum materials. In J. T. Remillard, B. A. Herbel-Eisenmann, \& G. M. Lloyd (Eds.), Mathematics teachers at work: connecting curriculum materials and classroom instruction (pp. 85-92). New York: Routledge.

Richardson, V. (1996). The role of attitudes and beliefs in learning to teach. In J. Sikula, T. Buttery, \& E. Guyton (Eds.), Handbook of research on teacher education (pp. 102-119). New York: Simon \& Schuster Macmillan.

Schommer, M. (1990). Effects of beliefs about the nature of knowledge on comprehension. Journal of Educational Psychology, 82, 498-504.

Seligman, M. E. P., \& Csikszentmihalyi, M. (2000). Positive psychology: an introduction. American Psychologist, 55(1), 5-14.

Simon, H. A. (1978). Information processing theory of human problem solving. In W. K. Estes (Ed.), Handbook of learning and cognitive processes (Vol. V, pp. 271-295). Hillsdale, NJ: Lawrence Erlbaum.

Stipek, D. J., Givvin, K. B., Salmon, J. M., \& MacGyvers, V. L. (2001). Teachers' beliefs and practices related to mathematics instruction. Teaching and Teacher Education, 17(2), 213-226.

Van den Akker, J. (2003). Curriculum perspectives: an introduction. In J. van den Akker, W. Kuiper, \& U. Hameyer (Eds.), Curriculum landscape and trends. Dordrecht: Kluwer Academic Publishers.

Van Driel, J. H., Beijaard, D., \& Verloop, N. (2001). Professional development and reform in science education: The role of teachers' practical knowledge. Journal of Research in Science Teaching, 38(2), 137-158.

Van Driel, J. H., Bulte, A. M. W., \& Verloop, N. (2007). The relationships between teachers' general beliefsabout teaching and learning and their domain specific curricular beliefs. Learning and Instruction, 17(2), 156-171.

Wilson, S. M. (2013). Professional development for science teachers. Science, 340(6130), 310-313. 